\title{
(2) OPEN ACCESS \\ Treatment-resistant schizophrenia characterised by dopamine supersensitivity psychosis and efficacy of asenapine
}

\author{
Nagara Takao, Toshiya Murai, Hironobu Fujiwara
}

Psychiatry, Kyoto University Hospital, Kyoto, Japan

\section{Correspondence to Dr Nagara Takao: takao.nagara@gmail.com}

Accepted 30 March 2021

Check for updates

(c) BMJ Publishing Group Limited 2021. Re-use permitted under CC BY-NC. No commercial re-use. See rights and permissions. Published by BMJ.

To cite: Takao N, Murai T, Fujiwara H. BMJ Case Rep 2021;14:e242495 doi:10.1136/bcr-2021242495

\begin{abstract}
SUMMARY
Dopamine supersensitivity psychosis (DSP) frequently arises with long-term antipsychotic treatment and accounts for a significant proportion of treatmentresistant schizophrenia. The mechanism underlying DSP is thought to be a compensatory increase in dopamine receptor density in the striatum caused by long-term antipsychotic treatment. Previous animal studies have reported that antipsychotics increase serotonin 5-HT2A receptor density in the striatum and that 5HT2A receptor blockers suppress dopamine-sensitive psychomotor activity, which may be linked to the pathophysiology of DSP. In this paper, we describe a patient who was hospitalised with treatment-resistant schizophrenia. Following treatment with high-dose antipsychotic polypharmacy for 10 weeks, the patient experienced worsening of psychotic and extrapyramidal symptoms. The patient was then started on secondgeneration antipsychotic asenapine while other antipsychotics were tapered off, resulting in improvement of these symptoms. Retrospectively, we presumed that the high-dose antipsychotic polypharmacy caused DSP, which was effectively treated by the potent $5-\mathrm{HT} 2 \mathrm{~A}$ receptor antagonism of asenapine.
\end{abstract}

\section{BACKGROUND}

Antipsychotics play a crucial role in the treatment of psychotic disorders, such as schizophrenia. However, their administration requires close monitoring because of their potential to induce a variety of adverse events, which include exacerbation of psychotic symptoms and side effects, such as drug-induced parkinsonism. Of note, dopamine supersensitivity psychosis (DSP) is thought to explain the phenomenon in which patients often relapse following slight dose reductions, discontinuation or switching of antipsychotics. Chouinard et al estimated that $50 \%$ of treatment-resistant schizophrenia cases are related to DSP. ${ }^{1}$ A possible mechanism is that long-term antipsychotic treatment causes a compensatory increase in dopamine receptor density in the striatum, which leads to a dopamine supersensitive state..$^{2-5}$ Moreover, recent studies have shown that the prevalence rate of DSP in patients with treatment-resistant schizophrenia in Japan is as high as $70 \%{ }^{6}$ The differences in the proportions of patients with DSP may be explained by the common use of high-dose antipsychotic polypharmacy in Japan. ${ }^{57}$ From the perspective of treatment strategies for DSP, one possible molecular mechanism involves the interaction between dopaminergic and serotonergic neurotransmission. Previous animal studies have reported that antipsychotics increase receptor density of serotonin 5-HT2A, a serotonergic receptor subtype, in the striatum and that 5-HT2A receptor antagonists suppress dopamine-sensitive psychomotor activity, which may be linked to the pathophysiology of DSP. ${ }^{8}$ We report a case of a male patient with schizophrenia, who developed DSP following high-dose antipsychotic polypharmacy. Symptoms improved following treatment with asenapine, an atypical antipsychotic that has high 5-HT2A antagonist binding potential.

\section{CASE PRESENTATION}

$\mathrm{Mr} \mathrm{A}$, a single man aged 44 years, suddenly ran outdoors 13 years earlier with the belief that he was contacting his old friend telepathically. He was referred to our hospital that year and we observed symptoms of delusions, hallucinations and castrophrenia. His previous medical history included purulent meningitis in infancy, hyperlipidaemia, hyperuricaemia, hypertension and obesity.

\section{TREATMENT}

He was diagnosed with schizophrenia (ICD-10 code F20.0) and started receiving antipsychotic therapy at our hospital. He was prescribed maximum doses of risperidone, olanzapine, quetiapine and aripiprazole at each previous hospitalisation because of a worsening of psychotic symptoms. These maximum doses were taken over to an outpatient setting and gradually reduced to $2 \mathrm{mg} /$ day of risperidone in the last year. He two times experienced rebound psychosis during switching of antipsychotics, 13 and 6 years earlier. The first episode occurred after switching $8 \mathrm{mg} /$ day of risperidone to $20 \mathrm{mg} /$ day of olanzapine and the second after switching $600 \mathrm{mg} /$ day of quetiapine to $20 \mathrm{mg} /$ day of olanzapine, during which oromandibular dyskinetic movement was observed. These symptoms, alongside a history of high-dose antipsychotic medication, suggest DSP at an earlier period. His latest hospital admission was voluntary and was because of a slight irritation (day 0). Because his symptoms were not causing significant distress, he was followed up without any changes in prescription. However, on day 7 , he developed prominent thought disorder, delusions of being injured by broken glass and a variety of visual and auditory hallucinations. Therefore, risperidone was increased to $8 \mathrm{mg} /$ day for the following 2 weeks, and quetiapine was initiated at 


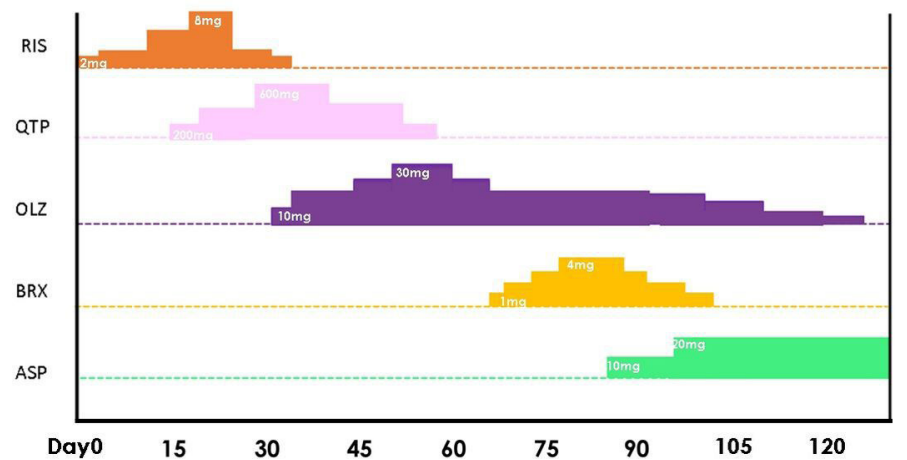

Figure 1 Reinforcement and replacement of antipsychotic medication worsened psychotic symptoms. Starting asenapine and tapering off other antipsychotics resulted in improvement of psychotic and extrapyramidal symptoms. ASP,asenapine; BRX, brexpiprazole; OLZ, olanzapine; QTP, quetiapine; RIS, risperidone.

$200 \mathrm{mg} /$ day (day 17) and slowly increased to $600 \mathrm{mg} /$ day over the next 2 weeks, with an expectation of anxiolytic and sedative drug effects. However, the patients showed inadequate response to these medications. From day 28, risperidone was gradually replaced with olanzapine, and at day 50, olanzapine was increased to $30 \mathrm{mg} /$ day. Despite temporary symptomatic improvement, we observed further aggravation of psychotic symptoms when chlorpromazine equivalence reached $1850 \mathrm{mg}$ (day 59). During the course of the abovementioned antipsychotic medication reinforcement and replacement (figure 1), he developed extrapyramidal symptoms (EPS) of akathisia and stuttering; the latter was suspected to be a tardive dyskinetic movement of the tongue. Given the risk of metabolic side effects and the inadequate sedative effect, quetiapine was tapered and discontinued, while brexpiprazole was gradually increased to $4 \mathrm{mg}$; however, the patient experienced no symptomatic improvement. We considered using clozapine because the patient met the definition of treatment-resistant schizophrenia, and evidence has suggested that clozapine is the treatment of choice for treatment-resistant schizophrenia. ${ }^{9-11}$ However, the patient's mother did not agree to the administration of clozapine because of fear of side effects, such as agranulocytosis. Finally, he was treated with asenapine, which was initiated at $10 \mathrm{mg} /$ day (day 84) and increased to $20 \mathrm{mg} /$ day (day 93). Olanzapine and brexpiprazole were tapered and discontinued.

\section{OUTCOME AND FOLLOW-UP}

Four weeks of treatment of $20 \mathrm{mg} /$ day of asenapine resulted in gradual improvement of psychotic symptoms and EPS. He subsequently willingly participated in an occupational therapy programme and was discharged on day 229.

\section{DISCUSSION}

In our patient, increasing antipsychotics worsened psychotic symptoms, which was against our expectations. He fulfilled the clinical characteristics of DSP, as reported by Chouinard et al, which are (1) improvement in acute psychotic symptoms, at least initially, by increasing antipsychotic dose, (2) at least 3 months of cumulative exposure to antipsychotics, (3) tolerance to antipsychotic effects, (4) rapid relapse following drug discontinuation, dose reduction or switching of antipsychotics, (5) worsening of psychotic symptoms with life stressors, such as minor life events or daily hassles, (6) appearance of new or more severe psychotic symptoms, (7) treatment resistance and (8) movement disorders, such as tardive dyskinesia. ${ }^{512}$ These symptoms were all observed during the most recent hospitalisation. However, his previous experiences of rebound psychosis and oromandibular dyskinetic movement during switching of antipsychotics suggest that he had developed DSP during an earlier period.

We question whether a period of 4 weeks for improvement of the established DSP state with asenapine was too short. A therapeutic course of several months is usually suggested for clinical cases of treatment-resistant schizophrenia with DSP. ${ }^{13}$ However, an animal study demonstrated rapid (within minutes to an hour) suppression of DSP-like activity using a 5-HT2A antagonist, ${ }^{8}$ which corresponds to several hours in humans. ${ }^{14}$ This may explain the rapid therapeutic effect induced by the agent in our patient. In light of this, it is possible that improvement of an established DSP state can be achieved within several days or weeks.

Several human studies have demonstrated that the underlying mechanism of DSP is a compensatory increase in dopamine D2 receptor density in the striatum caused by long-term administration of antipsychotics. ${ }^{45}$ Both lower and higher antipsychotic doses have been shown to induce dopamine supersensitive states in animal studies, but only the higher dose increased the number of striatal D2 receptors. ${ }^{315}$ Moreover, the relationship between DSP and 5-HT2A receptor function has also been demonstrated in an animal study that showed that chronic exposure to antipsychotic medications increases amphetamine-induced locomotion relative to antipsychotic-naïve rats, which is indicative of a dopamine supersensitive state. In contrast, ritanserin and MDL100,907, both 5-HT2A receptor antagonists, suppress locomotion in antipsychotic-treated rats. Additionally, haloperidol was shown to decrease 5-HT2A receptor density in the prelimbic cortex and nucleus accumbens core and increase 5-HT2A receptor density in the caudate-putamen. ${ }^{8}$ It should also be noted that asenapine exhibits the highest affinity for 5-HT2A receptors within second-generation antipsychotics. ${ }^{16}$ Given these findings, it is possible that, in our patient, DSP was induced by high-dose antipsychotic polypharmacy, and dopamine sensitivity was reduced by 5 -HT2A receptor blockade by asenapine. To date, there has only been one report that suggested a positive effect of asenapine on DSP, which was in a patient with delusional disorder whose DSP was thought to have been induced by ziprasidone. ${ }^{17}$

Other than the action on the 5-HT2A system, there are other antipsychotics profiles of note that are closely related to DSP: half-life period, affinity to dopamine D2 receptors and dopamine partial agonists. First, the instability of drug blood levels accounts for the instability of psychiatric symptoms. ${ }^{5}$ Long half-life period, sustained release or long-acting injectable 
antipsychotics are considered to be effective for preventing DSP because of the stability of blood drug levels. ${ }^{18}$ Half-life periods of representative antipsychotics are 20 hours for risperidone, ${ }^{19}$ 7 hours for quetiapine, ${ }^{20} 33$ hours for olanzapine, ${ }^{21} 91$ hours for brexpiprazole ${ }^{22}$ and 24 hours for asenapine. ${ }^{23}$ Asenapine has the advantage of a longer half-life period than that of risperidone or quetiapine. Second, antipsychotics that have higher affinity to dopamine D2 receptors are presumed to be effective in the treatment of DSP. ${ }^{24}$ Asenapine has higher affinity to dopamine D2 receptors than that of risperidone, quetiapine or olanzapine. ${ }^{11}{ }^{25-27}$ Finally, according to animal studies, a dopamine partial agonist is likely to be effective for DSP. ${ }^{28}{ }^{29}$ However, they may exacerbate psychotic symptoms in cases where DSP has already developed. ${ }^{30}$ This would explain why brexpiprazole, which is a dopamine partial agonist, was ineffective in our case.

In conclusion, this case presents an important clinical implication for use of antipsychotic agents. Both long-term use as well as high-dose polypharmacy of antipsychotics should be avoided as much as possible because of their potential to cause DSP due to increases in D2 receptor density and changes in 5-HT2A receptor density across various brain regions. Antipsychotics with strong 5-HT2A antagonism may be effective for the treatment of DSP.

\section{Learning points}

- This case presents an important clinical implication for the use of antipsychotic agents.

- Both long-term use and high-dose polypharmacy of antipsychotics should be avoided as much as possible because they may cause dopamine supersensitivity psychosis (DSP).

- Antipsychotics with potent 5-HT2A antagonism may be effective for DSP.

Contributors NT: manuscript preparation, preparation of images. TM: review \& editing. HF: primary consultant and revision of manuscript.

Funding The authors have not declared a specific grant for this research from any funding agency in the public, commercial or not-for-profit sectors.

Competing interests None declared.

Patient consent for publication Obtained.

Provenance and peer review Not commissioned; externally peer reviewed.

Open access This is an open access article distributed in accordance with the Creative Commons Attribution Non Commercial (CC BY-NC 4.0) license, which permits others to distribute, remix, adapt, build upon this work non-commercially, and license their derivative works on different terms, provided the original work is properly cited and the use is non-commercial. See: http://creativecommons.org/ licenses/by-nc/4.0/.

\section{REFERENCES}

1 Chouinard G, Chouinard V-A. Atypical antipsychotics: CATIE study, drug-induced movement disorder and resulting iatrogenic psychiatric-like symptoms, supersensitivity rebound psychosis and withdrawal discontinuation syndromes. Psychother Psychosom 2008:77:69-77.

2 Samaha A-N, Reckless GE, Seeman P, et al. Less is more: antipsychotic drug effects are greater with transient rather than continuous delivery. Biol Psychiatry 2008;64:145-52.

3 Samaha A-N, Seeman P, Stewart J, et al. "Breakthrough" dopamine supersensitivity during ongoing antipsychotic treatment leads to treatment failure over time. $J$ Neurosci 2007;27:2979-86
4 Silvestri S, Seeman MV, Negrete JC, et al. Increased dopamine D2 receptor binding after long-term treatment with antipsychotics in humans: a clinical PET study. Psychopharmacology 2000;152:174-80.

5 lyo M. Treatment-resistant schizophrenia and dopamine supersensitivity psychosis. Seishin Igaku 2018;60:291-9.

6 Suzuki T, Kanahara N, Yamanaka H, et al. Dopamine supersensitivity psychosis as a pivotal factor in treatment-resistant schizophrenia. Psychiatry Res 2015;227:278-82.

7 Xiang Y-T, Ungvari GS, Correll CU, et al. Trends in the access to and the use of antipsychotic medications and psychotropic co-treatments in Asian patients with schizophrenia. Epidemiol Psychiatr Sci 2016:25:9-17.

8 Charron A, Hage CE, Servonnet A, et al. 5-Ht2 receptors modulate the expression of antipsychotic-induced dopamine supersensitivity. Eur Neuropsychopharmacol 2015:25:2381-93.

9 Essali A, Al-Haj Haasan N, Li C, et al. Clozapine versus typical neuroleptic medication for schizophrenia. Cochrane Database Syst Rev 2009:CD000059.

10 Fakra E, Azorin J-M. Clozapine for the treatment of schizophrenia. Expert Opin Pharmacother 2012;13:1923-35.

11 Remington $\mathrm{G}$, Lee J, Agid 0 , et al. Clozapine's critical role in treatment resistant schizophrenia: ensuring both safety and use. Expert Opin Drug Saf 2016;15:1193-203

12 Chouinard G, Samaha A-N, Chouinard V-A, et al. Antipsychotic-Induced dopamine supersensitivity psychosis: pharmacology, criteria, and therapy. Psychother Psychosom 2017;86:189-219.

13 Kimura H, Kanahara N, Komatsu N, et al. A prospective comparative study of risperidone long-acting injectable for treatment-resistant schizophrenia with dopamine supersensitivity psychosis. Schizophr Res 2014;155:52-8.

14 Sengupta P. The laboratory rat: relating its age with human's. Int J Prev Med 2013:4:624-30.

15 Yin J, Barr AM, Ramos-Miguel A, et al. Antipsychotic induced dopamine supersensitivity psychosis: a comprehensive review. Curr Neuropharmacol 2017;15:174-83

16 Minassian A, Young JW. Evaluation of the clinical efficacy of asenapine in schizophrenia. Expert Opin Pharmacother 2010;11:2107-15.

17 Rajkumar RP. Supersensitivity psychosis and its response to asenapine in a patient with delusional disorder. Case Rep Psychiatry 2014;2014:1-3.

18 lyo M, Tadokoro S, Kanahara N, et al. Optimal extent of dopamine D2 receptor occupancy by antipsychotics for treatment of dopamine supersensitivity psychosis and late-onset psychosis. J Clin Psychopharmacol 2013;33:398-404.

19 Janssen Pharmaceuticals, Inc. Risperdal (risperidone) tablets and oral solution and Risperdal M-TAB (risperidone) orally disintegrating tablets prescribing information. Titusville, NJ, 2014

20 EMC. Quetiapine $25 \mathrm{mg}$ film-coated tablets - summary of product characteristics. Sandoz, 2013.

21 Callaghan JT, Bergstrom RF, Ptak LR, et al. Olanzapine. pharmacokinetic and pharmacodynamic profile. Clin Pharmacokinet 1999:37:177-93.

22 Eaves S, Rey JA, Brexpiprazole RJA. Brexpiprazole (Rexulti): a new monotherapy for schizophrenia and adjunctive therapy for major depressive disorder. PT 2016:41:418-22.

23 Scheidemantel T, Korobkova I, Rej S, et al. Asenapine for bipolar disorder. Neuropsychiatr Dis Treat 2015;11:3007-17.

24 Seeman P, Tallerico T. Antipsychotic drugs which elicit little or no parkinsonism bind more loosely than dopamine to brain D2 receptors, yet occupy high levels of these receptors. Mol Psychiatry 1998;3:123-34.

25 Leysen JE, Janssen PM, Megens AA, et al. Risperidone: a novel antipsychotic with balanced serotonin-dopamine antagonism, receptor occupancy profile, and pharmacologic activity. J Clin Psychiatry 1994:55:5-12.

26 Jensen NH, Rodriguiz RM, Caron MG, et al. N-Desalkylquetiapine, a potent norepinephrine reuptake inhibitor and partial 5-HT1A agonist, as a putative mediator of quetiapine's antidepressant activity. Neuropsychopharmacology 2008;33:2303-12.

27 Bymaster FP, Rasmussen K, Calligaro DO, et al. In vitro and in vivo biochemistry of olanzapine: a novel, atypical antipsychotic drug. J Clin Psychiatry 1997;58 Suppl 10:28-36

28 Tadokoro S, Okamura N, Sekine Y, et al. Chronic treatment with aripiprazole prevents development of dopamine supersensitivity and potentially supersensitivity psychosis. Schizophr Bull 2012;38:1012-20.

29 Amada N, Akazawa $H$, Ohgi Y, et al. Brexpiprazole has a low risk of dopamine $D_{2}$ receptor sensitization and inhibits rebound phenomena related to $D_{2}$ and serotonin 5- $\mathrm{HT}_{2 \mathrm{~A}}$ receptors in rats. Neuropsychopharmacol Rep 2019;39:279-88.

30 Kanahara N, Takase M, Sasaki T, et al. The effectiveness of very slow switching to aripiprazole in schizophrenia patients with dopamine supersensitivity psychosis: a case series from an open study. Int Clin Psychopharmacol 2020:35:338-44. 
Copyright 2021 BMJ Publishing Group. All rights reserved. For permission to reuse any of this content visit https://www.bmj.com/company/products-services/rights-and-licensing/permissions/

BMJ Case Report Fellows may re-use this article for personal use and teaching without any further permission.

Become a Fellow of BMJ Case Reports today and you can:

- Submit as many cases as you like

- Enjoy fast sympathetic peer review and rapid publication of accepted articles

Access all the published articles

- Re-use any of the published material for personal use and teaching without further permission

Customer Service

If you have any further queries about your subscription, please contact our customer services team on +44 (0) 2071111105 or via email at support@bmj.com.

Visit casereports.bmj.com for more articles like this and to become a Fellow 